\title{
Application and Research Twin Roll Casting-Extruding Process for Production Longish Deformed Semi-Finished Products from Aluminum Alloys
}

\author{
Sergey Sidelnikov ${ }^{1, a^{*}}$, Roman Galiev ${ }^{1}$, Andrey Bersenev ${ }^{1}$ \\ and Denis Voroshilov ${ }^{1}$ \\ ${ }^{1}$ Siberian Federal University, Russia, 660025, Krasnoyarsk, Krasnoyarskiy Rabochiy ave., 95, \\ Russia \\ asbs270359@yandex.ru
}

\begin{abstract}
Keywords: aluminum alloys, twin roll casting-extruding, rolls, matrix, longish deformed semifinished products, drawing ratio, mechanical properties, technical and economic indicators
\end{abstract}

\begin{abstract}
At present, Russia is actively developing methods of combined treatment of aluminum alloys, one of which is the method of twin roll casting-extruding. It is very suitable for processing aluminum alloys having a relatively low melting point. The method consists in pouring a melt into the rotating rolls, crystallizing it on the roll surfaces, rolling with a predetermined reduction amount, pressing out in front of the die and squeezing out the product of the predetermined configuration and dimensions through it with drawing ratio in the range of values 10-40. Analysis of technical and economic indicators showed that this method has a number of advantages in comparison with traditional technologies of semicontinuous extruding and continuous castingrolling. So the output of a good metal at high production volumes can reach $95-97 \%$ at a productivity of up to 3-4 tons per hour. In addition, it is possible to quickly move from one profile size to another by changing the matrix. The authors proposed and patented various designs and methods for producing solid and hollow press products from non-ferrous alloys. On their basis, laboratory and pilot-industrial units for combined processing have been created, on which experimental studies have been carried out to obtain long-dimensioned deformed semi-finished products from aluminum alloys series $5 \mathrm{xxx}, 6 \mathrm{xxx}, 8 \mathrm{xxx}$ and others. The energy-power parameters of the process are determined and found that they are significantly smaller in comparison with traditional technologies (in 10-50 times). Investigations of the mechanical characteristics of press products have been carried out, which showed that when implementing such a treatment scheme, even when producing extruded products from low-plastic alloys, they have a high level of plastic and strength properties. Developed technologies based on the method twin roll casting-extruding now are tested in a laboratory of combined treatment methods in School of Non-ferrous Metals and Material Science in Siberian federal university and industrial conditions of a number of metallurgical plants.
\end{abstract}

\section{Introduction}

Longish deformed semi-finished products from aluminum alloys series 5xxx, 6xxx, 8xxx and others widely used in electrical engineering, shipbuilding, rocket and space technology and other areas of industry. The creation of technologies for their processing and research of the properties of products from them is devoted to numerous works of domestic and foreign scientists [1-13].

The schemes of combined treatment of aluminum and its alloys with the use of injection molding and metal forming operations are currently the main ones for the production of long billets with a small cross-sectional area in order to form a fine-grained structure of the casting due to high crystallization rates and subsequent metal deformation in rolls. The first of them were introduced the methods of continuous casting and rolling [1,2]. They use roller (rotary) molds and multi-mill rolling mills, which allow obtaining products in the form of wire rod of the required quality and with high productivity. These schemes have undeniable technical and economic advantages as compared to traditional technologies the number of subsequent metal processing operations is 
reduced. When casting into roller molds, the metal is poured into the caliber of the rotating rolls, solidifies therein, and undergoes deformation between the rolls. Roller unit with water-cooled rolls are distinguished by methods of feeding the metal into the rolls: from the side, from above and from below. For the production of sheet metal, the molten metal is fed into the solidification zone along the channel and under the action of the metallostatic pressure, enters the gap between the rolls, which are cooled by water circulating along their internal channels. Getting into the distributive box, the metal is evenly distributed throughout the length of the nozzle and rolls, and when it comes into contact with the surface of the rolls it solidifies and is subjected to hot deformation [3].

To produce continuous castings of round, rectangular, square and other shapes, the rolls are calibrated, and the dimensions and shape of the workpiece are determined by the cavity formed by the two rolls when they are aligned with each other. However, in this case, especially for large gauge sizes, it is quite difficult to organize a continuous casting process, since molten metal may not crystallize in rolls if the technological constraints are not observed. Such crystallizers are advisable to use for combined processes of metal treatment, when the roll caliber at their output is covered by a press tool - a matrix (Fig. 1.). For the preparation of press products, it is possible to treat the preformed cast preform in a solid state (Fig. 1.1,a) and metal treatment in the solid-liquid state (Fig. 1.1, b). In connection with the fact that in the latter case there is a high-speed crystallization-deformation of the metal in the rolls and its extrusion through the matrix, this method was called the method of combined casting and rolling-extruding (CCRE) [4].

Technical and technological developments. However, these methods also include the successive processing of an ingot obtained by continuous casting into a rotary or electromagnetic crystallizer [4] and subsequent processing by rolling and pressing operations. In connection with this, the method of metal processing, which consists of pouring liquid metal into rotating rolls and its crystallization-deformation (Fig. 2), was termed the twin roll casting-extruding (TRCE).

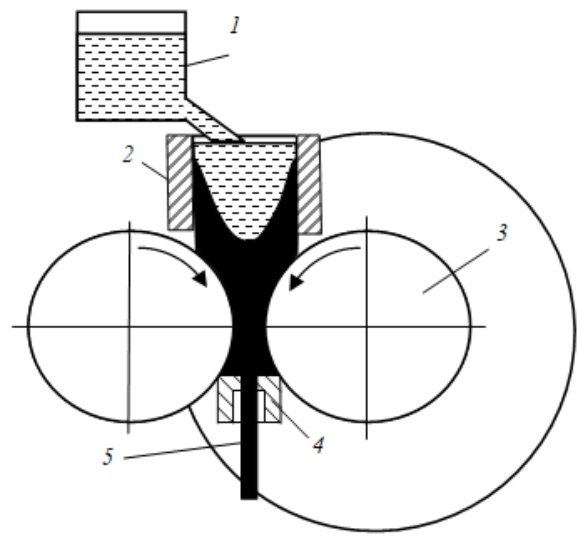

$a$

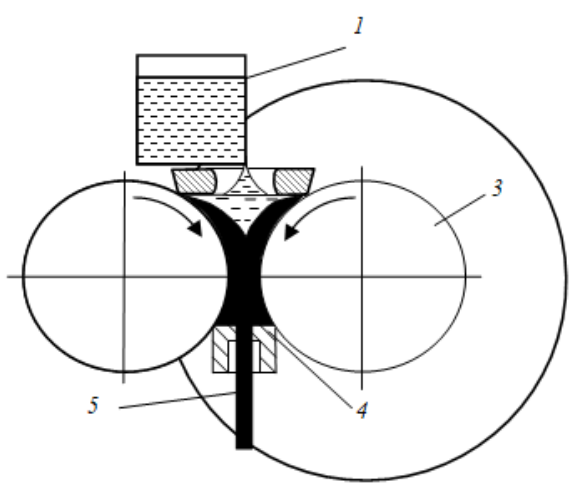

$b$

Fig. 1. Schemes of crystallization-deformation of metal: $a-$ in solid state; $b-$ in liquid state; 1-holding furnace; 2 - crystallizer; 3 -rolls; 4 - matrix; 5 - extruded product

In the scientific-technical and patent literature there are quite a few different types of units for the production of long products made of aluminum alloys by this method.

One of the first was proposed the design of the device for twin roll casting-extruding (Fig. 2) under the patent [14]. In this case, the melt is poured directly into the crystallizer rolls of the unit, crystallizes in the form of a rectangular preform, is deformed by the same rolls, and then extruded through the calibration opening of the matrix.

A distinctive feature of this device is that it is equipped with a long-sized needle installed coaxially with a matrix with a retraction mechanism rigidly fixed with a detent and located in a cage with lubrication channels located along the perimeter of the needle and protrusions for locking channels. In this case, the rolls are made with water-cooled cavities. 

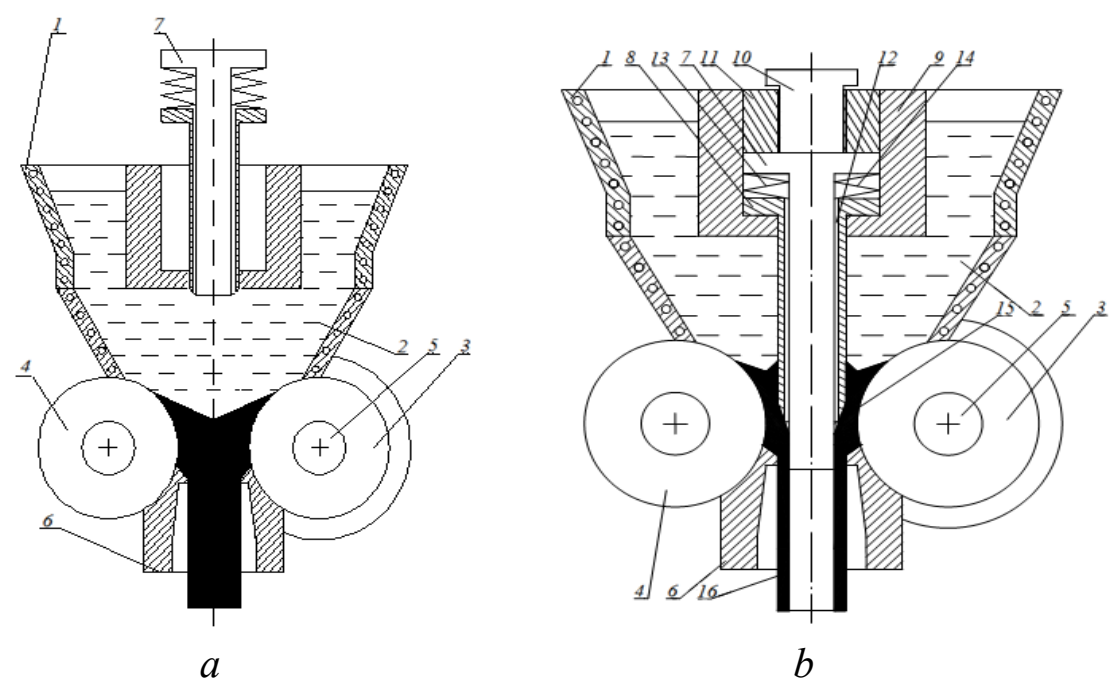

Fig. 2. Device for twin roll casting-extruding solid $(a)$ and hollow $(b)$ extruded products under the patent [14]: 1 - holding furnace; 2 - melt; 3 - roll with a stream; 4 - roll with the protrusion; 5 - water-cooled cavities; 6 - matrix; 7 - needle; 8 - collar; 9 - clamp; 10 - screw; 11 - holder; 12 - channels for lubricant supply; 13,14-springs; 15 - crystallized metal; 16 - extruded product

The device (Fig. 3) in accordance with the patent [15] allows expanding technological possibilities due to an increase in yield, reduction of metallurgical processing cycles, reduction of labor and energy intensity of the process, and also improvement of the quality of extruded products due to improvement of mechanical properties. Unit for continuous casting, rolling and extruding of metal (Fig. 3) include holding furnace 1 with regulator 2 for feeding the melt into the roll caliber, roll 3 with a stream and roll 4 with protrusion, located in the frame 5, having cavities 6 for cooling and forming a closed caliber, overlapped at the output by a matrix 7 with wedge-shaped cavities for cooling 8 . To push the matrix to the rolls, there is a wedge mechanism 9 , fitted with guide rollers 10. Behind them is a coiler 11, which ensures the coiling of the finished extruded product in the bay. The device works as follows. Metal, melted with holding furnace 1, captured by rolls 3 and 4 . In operation, the regulator 2 doses the amount of metal fed into the roll caliber, reducing or increasing the melt flow. At the same time, crystallization of the metal begins on the surfaces of the water-cooled rolls 3,4. Then, the metal crystallized in the form of a blank is crimped in a closed caliber, pressed before the matrix 7 , and extruded into the calibration hole of the die to form an extruded article of the specified shape and dimensions. The output end of the moving press product enters the guide rollers 10 , which change its direction of travel by $90^{\circ}$ and transferred to the coiler 11 , where the coiling is performed in the coil. 


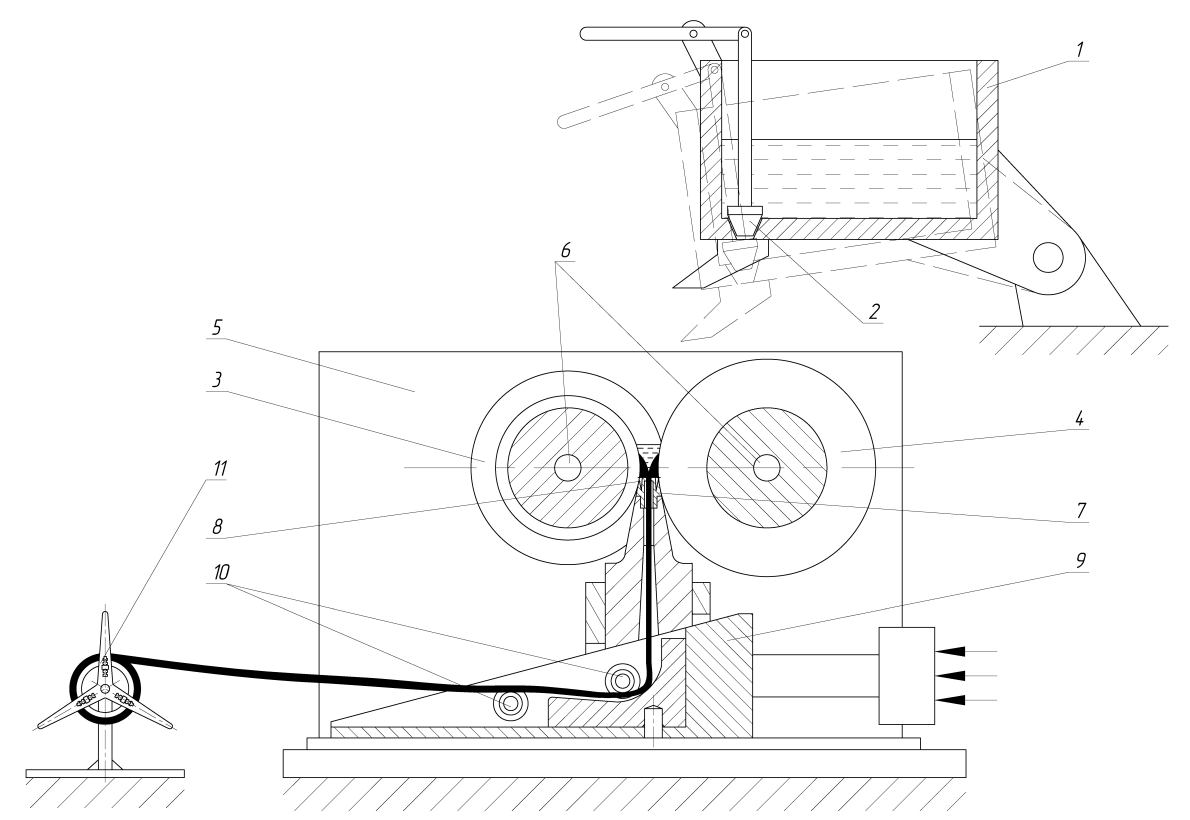

Fig. 3. Device for continuous casting, rolling and extruding using a two-roll crystallizer: 1 - holding furnace; 2 - regulator; 3 - roll with a stream; 4 - roll with the protrusion; 5 - frame; 6 - cavity for cooling of rolls; 7 - matrix; 8 - wedge-shaped cavities; 9 - clamping mechanism; 10 - guide rollers; 11 - coiler

On the basis of the above technical solutions the unit of combined casting and rolling-extruding CCRE-2,5 was designed and manufactured [16], on which a number of experimental studies on obtaining longish deformed semi-finished products from an aluminum alloy 6082 realized.

\section{Experimental Research}

The purpose of the research was to access the feasibility of implementing a new technology to produce calibrated bars from alloy 6082, to determine the mechanical properties of deformed semifinished products and to compare them with the requirements of international standards, and to compare the technical and economic indicators of the new technology.

To achieve this goal, experimental studies were carried out to obtain rods from alloy 6082 using the technology of combined casting, rolling-extruding on unit CCRE-2,5. The temperature of the melt in the mixer was $750^{\circ} \mathrm{C}$. The rotation speed of the rolls was $4 \mathrm{rpm}$, while their cooling with water was used. As a result, a rod of alloy 6082 with a diameter of $9 \mathrm{~mm}$ was obtained (the actual size is within the range of 8.86-8.89 mm). Its length in the bay was $30 \mathrm{~m}$, and the baying was done manually. Cooling of the rod was also carried out by water jetting.

A part of a $1.3 \mathrm{~m}$ long rod was machined on an AVS25 cogging machine and subjected to drawing. The carriage speed was $20 \mathrm{~m} / \mathrm{min}$. The dimensions of the rod after drawing were in the range 7.98-7.99 $\mathrm{mm}$. The drawing was carried out on a linear drawing mill with a force of $50 \mathrm{kN}$ from a diameter of $9 \mathrm{~mm}$ to a diameter of $8 \mathrm{~mm}$. The draw ratio in this case was 1,26; degree of deformation was $20,85 \%$. The heat treatment of rods was carried out in laboratory conditions according to the following conditions: quenching temperature $T_{q}=535^{\circ} \mathrm{C}$ and duration $\tau_{\text {hold }}=20 \mathrm{~min}$; ageing temperature $T_{a}=160^{\circ} \mathrm{C}$ and duration $\tau_{\text {hold }}=10 \mathrm{~h}$.

From the obtained rods, barbell samples were made with a working length of $35 \mathrm{~mm}$ and a diameter of $7 \mathrm{~mm}$, which were subjected to tensile tests at room temperature. At the same time on a universal machine LFM 400 (Fig. 4, Table 1) The samples were torn at a deformation rate of $20 \mathrm{~mm} / \mathrm{min}$ and measured ultimate tensile strength $R_{m}$, yield strength of metal $R_{P}$ and elongation to failure $A$. 
In determining the strength and plastic properties of the samples, the change in the length of the working part of the sample was recorded each time, and also the value of the tensile force $P$ corresponding to this change.

Then, ultimate tensile strength $R_{m}$ and elongation to failure $A$ were determined from the known formulas:

$$
R_{m}=\frac{P}{S_{0}} ; \quad A=\frac{L_{u}-L_{0}}{L_{0}} \cdot 100 \%
$$

where $P$ - The maximum tensile force over the whole area of plastic deformation of the sample, preceding the moment of neck formation; $S_{0}$ - initial cross-sectional area; $L_{0}$ - initial length of the working section of the sample; $L_{u}$ - length of the working section of the sample after the test.

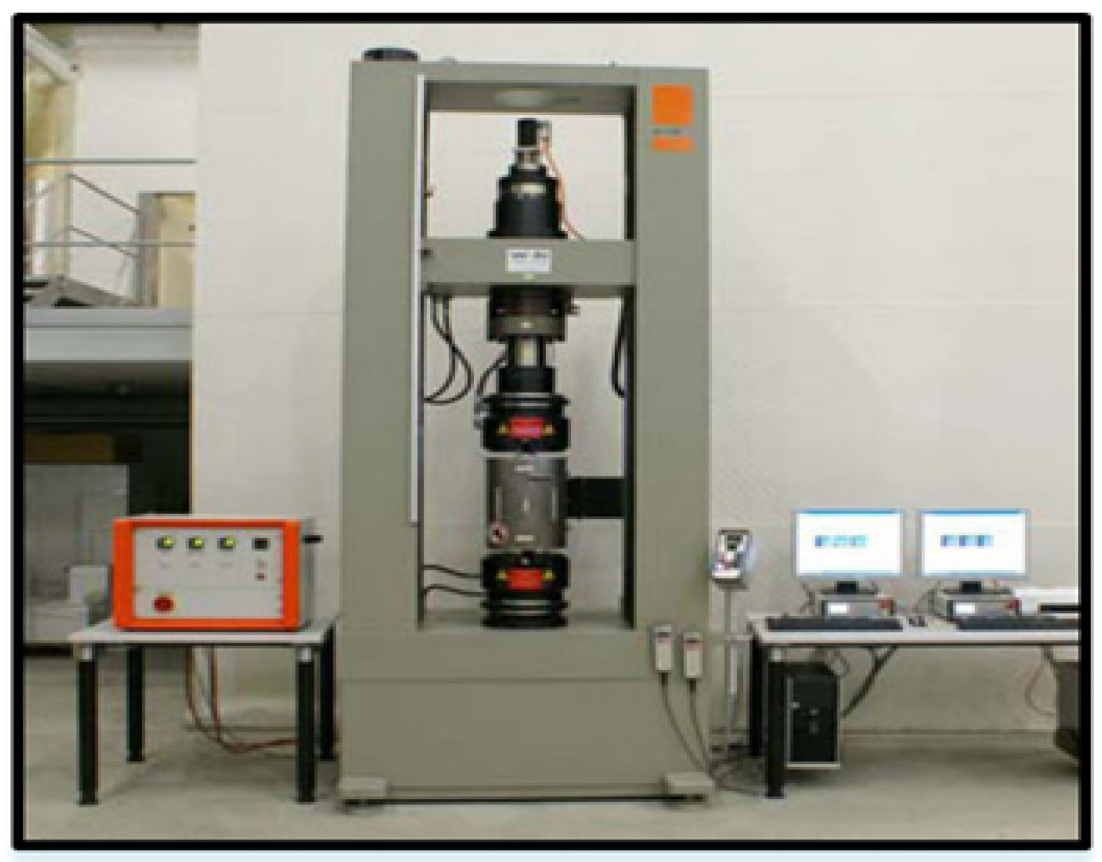

Fig. 4. General view of the universal testing machine LFM400

Table 1. Technical characteristics of universal testing machine LFM400

\begin{tabular}{|l|c|}
\hline \multicolumn{1}{|c|}{ Characteristic } & Value \\
\hline Maximum static force, $\mathrm{kN}$ & 400 \\
\hline Maximum speed, $\mathrm{mm} / \mathrm{min}$ & 500 \\
\hline Stroke crosshead, $\mathrm{mm}$ & 1000 \\
\hline Maximum distance between grippers, $\mathrm{mm}$ & 800 \\
\hline Distance between columns, $\mathrm{mm}$ & 700 \\
\hline Working height, $\mathrm{mm}$ & 720 \\
\hline
\end{tabular}




\section{Results}

The results of testing the mechanical properties of rods obtained by the TRCE technology in hotextruded and heat-treated state are presented in Table 2.

Table 2. Mechanical properties of rod with diameter $9 \mathrm{~mm}$ from alloy 6082

\begin{tabular}{|c|c|c|c|c|}
\hline Condition & $\begin{array}{l}\text { Bar length selection } \\
\text { zone, } \mathrm{mm}\end{array}$ & $\begin{array}{l}\text { Ultimate } \\
\text { tensile strength } \\
R_{m}, \mathrm{MPa} \\
\end{array}$ & $\begin{array}{l}\text { Yield } \\
\text { strength } R_{P}, \\
\quad \mathrm{MPa} \\
\end{array}$ & $\begin{array}{c}\text { Elongation to } \\
\text { failure } A, \%\end{array}$ \\
\hline \multirow[t]{3}{*}{ hot-extruded } & output & 285 & 165 & 22,2 \\
\hline & middle & 213 & 133 & 23,8 \\
\hline & in the end & 210 & 126 & 25,3 \\
\hline \multirow[t]{6}{*}{ heat-treated } & output & 397 & 294 & 15,6 \\
\hline & & 369 & 258 & 14,0 \\
\hline & middle & 386 & 326 & 15,6 \\
\hline & & 373 & 305 & 15,8 \\
\hline & in the end & 371 & 307 & 10,7 \\
\hline & & 378 & 315 & 12,4 \\
\hline \multicolumn{2}{|c|}{$\begin{array}{l}\text { Requirements for EN } 755-2 \text { for } \\
\text { extruded rods } \varnothing \text { to } 25 \mathrm{~mm} \text { from alloy } \\
6082 \text { in condition T6 }\end{array}$} & $\geq 295$ & $\geq 250$ & $\geq 8$ \\
\hline
\end{tabular}

The test results showed that the rod from alloy 6082 made on the unit CCRE-2,5, after hardening heat treatment has sufficiently high values of strength characteristics. The mechanical properties of the rod after heat treatment satisfy the requirements of EN 755-2.

The mechanical properties of the drawn rod were tested in a cold-worked and thermo-hardened state. The results of tests of their mechanical properties are given in Table 3.

Table 3. Mechanical properties of a drawn rod with a diameter of $8 \mathrm{~mm}$ from alloy 6082

\begin{tabular}{|c|c|c|c|}
\hline Condition & $\begin{array}{c}\text { Ultimate } \\
\text { tensile strength } \\
R_{m}, \mathrm{MPa}\end{array}$ & $\begin{array}{c}\text { Yield } \\
\text { strength } R_{P}, \\
\mathrm{MPa}\end{array}$ & $\begin{array}{c}\text { Elongation to failure } \\
A, \%\end{array}$ \\
\hline hot-extruded & 290 & 268 & 12,0 \\
& 284 & 260 & 12,3 \\
& 269 & 251 & 12,0 \\
\hline heat-treated & 331 & 268 & 16,0 \\
& 327 & 264 & 18,5 \\
& 335 & 276 & 16,5 \\
& 343 & 287 & 19,5 \\
& 343 & 280 & 17,5 \\
Requirements for EN 755- 2 for & $\geq 310$ & 276 & $\geq 10,7$ \\
extruded rods $\varnothing$ to 25 mm from & & & \\
alloy 6082 in condition T6 & & & \\
\hline
\end{tabular}

It can be seen that the strength and plastic properties after quenching and ageing significantly increase, which is associated with the formation during the quenching of a supersaturated solid solution of aluminum and its decomposition after ageing, with the release of strengthening phases for thermally hardened aluminum alloys [17]. The data obtained correspond to the level of mechanical properties for the alloy and its analogues, cited in the reference literature $[17,18]$ and standard EN 754-2.

On the basis of the conducted studies, the technical and economic indices of twin roll castingextruding were evaluated in comparison with the traditional technology of rod production by the method of direct extruding on hydraulic extruders used at one of the leading metallurgical plants in Russia. These indicators are given in Table 4. 
Analysis of technological processes and calculations of economic indicators for the two technologies (traditional and new) give the opportunity to argue that, both in terms of labor intensity (11 operations instead of 25), and at cost, the new technology TRCE has an advantage over traditional. The calculation of the cost was carried out according to the shop costs of one of the Russian metallurgical enterprises in rubles for the production of 1 ton of products in the form of calibrated rods from alloy 6082 .

Table 4. Comparative technical and economic indicators of traditional and new technology of twin roll casting-extruding

\begin{tabular}{|l|c|c|}
\hline \multicolumn{1}{|c|}{ Indicators } & $\begin{array}{c}\text { Traditional extruding } \\
\text { technology }\end{array}$ & TRCE technology \\
\hline The yield, \%: & 77 & 96 \\
melting; & 63 & 97 \\
extruding & 832 & 95 \\
\hline Electricity, kW·h on 1 ton: & 5303 & 3073 \\
melting; & 10042 & 18689 \\
extruding & 2300 & - \\
\hline Recycling, RUR/ton: & 36409 & 28446 \\
melting; & 28446 & 163692 \\
additional remelting & 193754 & 30062 \\
extruding; & & \\
drawing & & \\
\hline Cost price at variable costs, RUR & & \\
/ton & & \\
\hline Reducing the cost price, RUR /ton & & \\
\hline
\end{tabular}

The analysis of technological processes and the calculation of economic indicators using two technologies (traditional and new) make it possible to state that the new technology of twin roll casting-extruding has an advantage over both conventional (11 operations instead of 25) and cost.

\section{Conclusion}

Thus, the conducted studies allowed asserting the following:

- realization of the process of twin roll casting-extruding to produce products in the form of longish deformed semi-finished products of aluminum alloys is practically possible;

- the mechanical properties of a rod $9 \mathrm{~mm}$ in diameter, obtained by the method of twin roll casting-extruding from alloy 6082, after heat treatment satisfy the requirements of EN 755-2;

- the mechanical properties of a wire obtained from a rod manufactured by the TRCE method are in accordance with the requirements of EN 754-2;

- the labor intensity of production and the cost of production in the form of calibrated bars of alloy 6082, obtained by the method of twin roll casting-extruding is lower in comparison with the traditional technology of direct extruding on hydraulic extruders, which gives grounds to recommend it for introduction into production. 


\section{References}

[1] Shevakin Yu.V., Krucher G.N., Development of continuous and combined processes of casting and rolling non-ferrous metals on casting and rolling units, Tsvetnie metalli. 5 (1997)71-74.

[2] Kantselson M.P., Casting and rolling units for the production of wire rod from non-ferrous metals: overview. 1(1) (1990) 40.

[3] Cherniak S.N., Kovalenko P.A., Simonov V.N., Twin roll casting of aluminum strip, M.: Metallurgiya, 1976.

[4] S.B. Sidelnikikov, N.N. Dovzhenko, N.N. Zagirov, Combined and complex methods of machining non-ferrous metals and alloys, M.: MAKS PRESS, 2005.

[5] Bayat N., Carlberg T., Influence of Heat Treatment on the Surface Structure of 6082 Al Alloys, Metallurgical and Materials Transactions A: Physical Metallurgy and Materials Science. 48(10) (2017) 5085-5094.

[6] Hanke S., dos Santos J.F., Comparative study of severe plastic deformation at elevated temperatures of two aluminium alloys during friction surfacing, Journal of Materials Processing Technology. 247 (2017) 257-267.

[7] Xuanzhen C., Yong P., Shan P., Song Y., Chao C., Ping X., Flow and fracture behavior of aluminum alloy 6082-T6 at different tensile strain rates and triaxialities, PLoS ONE. 12(7) (2017) e0181983.

[8] Kumar V., Kumar D., Investigation of tensile behaviour of cryorolled and room temperature rolled $6082 \mathrm{Al}$ alloy, Materials Science and Engineering A. 691 (2017) 211-217.

[9] Mallela K., Ilinich A., Luckey S., Zeng D., Gan Y., Characterization of 6XXX Series Aluminum Extrusions Using Digital Image Correlation (DIC) technique, SAE Technical Papers. 2017 March (2017), DOI: 10.4271/2017-01-0316.

[10] Wang P.L., Jiang H.T., Zhang R.J., Huang S.Y., Study of hot deformation behavior of 6082 aluminum alloy. Materials Science Forum. 877 (2017) 340-346.

[11]Li H.-B., Li X.-L., Xu S.-C., Lin Z., The flow stress curve correction and constitutive equation of 6082 aluminum alloy under thermal deformation, Suxing Gongcheng Xuebao/Journal of Plasticity Engineering. 23(3) (2016) 153-159.

[12]Negendank M., Taparli U.A., Gall S., Müller S., Reimers W., Microstructural evolution of indirectly extruded seamless 6XXX aluminum tubes with axial variable wall thickness, Journal of Materials Processing Technology. 230 (2016) 187-197.

[13]Ebrahimi M., Gholipour H., Djavanroodi F., A study on the capability of equal channel forward extrusion process, Materials Science and Engineering A. 650 (2016) 1-7.

[14]S.B. Sidelnikov, N.N. Dovzhenko, A.V. Eshkin, RF Patent 2100136 IPC B22D 11/06, B21C 23/00, Installation for continuous casting and extruding of metal. (1997)

[15] S.B. Sidelnikov, N.N. Dovzhenko, E.S. Lopatin [and others] RF Patent 73245, IPC B21C 3/00, B22D 11/00, Device for continuous casting, rolling and extruding of non-ferrous metals and alloys. (2008)

[16]Nikolai Dovzhenko, Sergey Sidelnikov, Ivan Dovzhenko, Roman Galiev, New Technology of Combined Machining of Aluminum Alloys, Key Engineering Materials. 746 (2017) 29-35.

[17]John E. Hatch (Eds.): Aluminum properties and physical metallurgy, American society for metals, 1984.

[18]N.A. Grishchenko, S.B. Sidelnikikov, I.Yu, Gubanov, E.S. lopatina, R.I. Galiev, Mechanical properties of aluminum alloys: monography, Krasnoyarsk : SibFU, 2012. 